\title{
Regulatory Realities and Hopes
}

\author{
VELVET G. MILLER
}

New Jersey Department of Human Services, Trenton

ROYEN A. BRENNAN DESCRIBES HOW REGULATION
could go some distance toward closing the regrettable gap between
the worlds of health services research and quality oversight. Although Brennan concludes that the various mechanisms of regulation have done little to improve the quality of health care, readers who are engaged in quality oversight may benefit from his review and synthesis of the theory and regulatory approaches that are now current in the health care industry. The theory of "responsive regulation" may be of particular interest to those who are willing to step back from their usual daily activities to appraise critically the workings of their organizations and to consider the possibilities of its application.

The adversarial dynamics of the relationship between regulators and the health care industry are costly, in both human and fiscal terms. Responsive regulation offers a new kind of relationship, which, by its very nature may do more to assure quality improvement than current practices can achieve. This is no small challenge.

The first requirement of this changing dynamic is the existence of a collective will to establish a different regulatory environment, one that is collegial, that deals promptly with quality deficiencies and applies disciplinary actions equitably, that is inclusive in establishing standards and guidelines, and that fosters shared learning and creativity.

The Milbank Quarterly, Vol. 76, No. 4, 1998

(C) 1998 Milbank Memorial Fund. Published by Blackwell Publishers, 350 Main Street, Malden, MA 02148, USA, and 108 Cowley Road, Oxford OX4 1JF, UK. 
The second major requirement entails a dramatic transformation of three major facets of oversight: the people, the process, and the politics. To tackle the first, the most senior leaders of an organization would have to send a clear message and supply persistent direction to ensure that all levels of staff continue to collaborate on quality improvement. Addressing the second aspect would call for an emphasis on the shared goal of progress toward demonstrable improvement in the quality of health care and a de-emphasis of protection of turf. To carry out the third facet, it would be necessary to lift the constraints of policies and procedures that result in bureaucratic inertia and to eliminate conflicting regulations and overlapping jurisdictions.

In addition, application of this model would require courageous action by legislators at all levels of government and by the most senior public officials to intentionally incorporate research findings and analyses of issues into policy. Unfortunately, we continue to witness legislation by body part or disease that does little to advance the quality of health care. We also continue to encounter resistance to implementing programs like needle exchange, despite extensive study and empirical evidence of their effectiveness. Regrettably, decisions are fueled by political expediency and the whims of public sentiment, rather than by sound analyses.

The formidable challenges to the overseers of quality are only equaled by those confronting a health care industry ensconced in the competitive market model. Unfettered competition historically has presented considerable risks for consumers. Safe havens for creativity are unlikely to be encouraged or embraced in this volatile industry, which is guided by a Darwinian view of survival. It would be interesting to posit Brennan's advocacy of controlled regulation as a counterbalance to Enthoven's concern about the stunting effect of any form of regulation.

The author did not mention an emerging form of regulation and oversight: contracting. Public purchasers of health services for the Medicaid and other programs are turning more frequently to this approach for dealing with managed care organizations. The comprehensive study recently completed by Sarah Rosenbaum (1998) reveals the number of states that are effectively using this mechanism for oversight, particularly of access and improvement of the quality of care for low-income people. Further study would include these questions: (1) Is this is a more effective way to exact desired outcomes for quality? (2) Can the consistent application of agreed-upon expectations be required and written into the contracts of public and private purchasers? 
Although the current structures of quality oversight have been ineffective to this point, there has been little attention paid to the role of self-advocacy and the power and influence of an informed consumer. Inclusion of consumers in the regulatory process may act as powerful reminder of the ultimate purpose of our efforts: improved care and better outcomes for the people we serve.

Regulators may be dissuaded from taking Brennan's recommendations seriously. Changing a multifaceted system requires confronting the inevitable conflicts and competing interests in the health care industry, certainly a daunting task. Nevertheless, some states have successfully used strategies derived from the "responsive regulations" philosophy. We can only hope that they represent the wave of the future.

\section{Reference}

Rosenbaum, S., B. Smith, P. Shin, et al. 1998. Negotiating the New Health System: A Nationwide Study of Medicaid Managed Care Contracts, 2nd ed., ed. K. Johnson. Washington, D.C.: Center for Health Policy Research, George Washington University Medical Center.

Address correspondence to: Dr. Velvet Miller, Executive Director, Children’s Futures New Jersey, 100 Canal Pointe Boulevard, Suite 112, Princeton, NJ 08540. 